\title{
Tricuspid valve replacement for Ebstein's anomaly A 19 year review of the first case
}

\author{
RICHARD G CHARLES, * CHRISTIAAN N BARNARD, WALTER BECK \\ From the Departments of Medicine and Cardiac Surgery, Groote Shuur Hospital, Cape Town, South Africa
}

SUMMARY The first published case of tricuspid valve replacement for Ebstein's anomaly is reviewed 19 years after operation. Valve replacement without ventricular plication remains our policy in all age groups.

Nineteen years have elapsed since the first successful surgical correction of Ebstein's anomaly by tricuspid valve replacement was achieved in 1962. ${ }^{1}$ The operation of choice, however, remains controversial but frequently the duration of follow-up after operation in reported cases is short. While the first report of a particular condition or procedure is invariably quoted by subsequent authors, it is rare for the long term fate of that patient to be documented. We have recently reviewed the recipient of the first tricuspid valve replacement for Ebstein's anomaly and present the findings as a contribution to the continuing debate.

\section{Case report}

The patient, a Coloured boy, underwent surgery in 1962 at the age of $4 \frac{1}{2}$ years for refractory heart failure with increasing cyanosis, cardiomegaly, and physical disability. The tricuspid valve, which was regurgitant and obstructed right ventricular outflow, was replaced by a University of Cape Town $3.8 \mathrm{~cm}^{2}$ prosthesis inserted at the position of the true annulus proximal to the atrialised segment and the coronary sinus. The postoperative course was uncomplicated and by the third month the child was asymptomatic, acyanotic, and in good health.

SUBSEQUENT PROGRESS

Clinical state

The dramatic symptomatic improvement has been maintained without interruption until his recent

* Present address: Regional Cardiac Centre, Sefton General Hospital, Smithdown Road, Liverpool review in June 1980. He developed normally throughout childhood and adolescence, leaving school at 16 years. His only symptoms have been mild breathlessness on running and occasional brief palpitations.

At the last review he was in sinus rhythm, his blood pressure was $130 / 90 \mathrm{mmHg}$, and the jugular venous pulse was just visible with equal ' $a$ ' and ' $v$ ' waves and no cyanosis. There were no murmurs. The heart sounds were normal with clear prosthetic clicks and a delayed tricuspid opening sound.

\section{Chest $x$-ray}

A striking reduction in heart size after operation has been maintained. In 1975 the cardiothoracic ratio was 54 per cent and at the last review was 56 per cent, both films showing right atrial enlargement and normal pulmonary vascularity (Fig. 1).

\section{Electrocardiogram}

The electrocardiogram one year after operation showed the development of incomplete right bundlebranch block. Sinus rhythm was maintained with a normal PR interval of 160 milliseconds (Fig. 2A). In 1975, there was sinus rhythm with a PR interval of 240 milliseconds, but no further broadening of the incomplete right bundle-branch block. Right atrial hypertrophy was more pronounced. These findings were unchanged at the latest review (Fig. 2B).

\section{Haemodynamics}

Cardiac catheterisation was performed in 1975 as part of a pre-employment review. The findings are shown in the Table. No shunts were detected. The right 


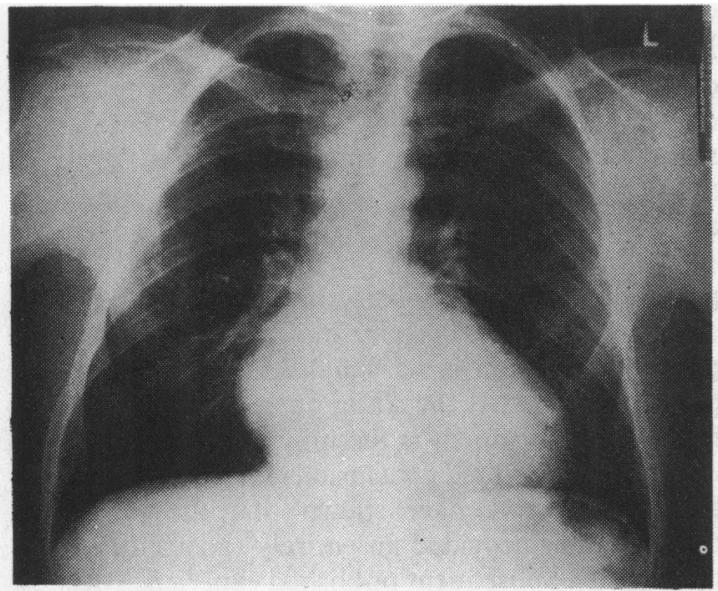

Fig. 1 Chest $x$-ray film in 1980 showing cardiothoracic ratio 56 per cent, right atrial enlargement, and normal pulmonary vascularity.

atrium was large and showed moderate contractility while the atrialised portion acted as a non-contractile blood reservoir. There was no tricuspid prosthetic regurgitation.

\section{Discussion}

The severity of Ebstein's anomaly varies from a barely detectable abnormality with a normal life expectancy to a disabling condition with early mortality. In our
Table Haemodynamic findings

\begin{tabular}{|c|c|c|}
\hline & \multicolumn{2}{|c|}{ Pressure $(\mathrm{mmHg})$} \\
\hline & Phasic & Mean \\
\hline Right atrium & a $16 \mathrm{v} 12$ & $\overline{10}$ \\
\hline Right ventricle & $24 / 2-6$ & \\
\hline Pulmonary artery & $24 / 11$ & $\underline{17}$ \\
\hline Brachial artery & $100 / 50$ & $\overline{75}$ \\
\hline $\begin{array}{l}\text { Tricuspid prosthetic } \\
\text { gradient }\end{array}$ & & $\overline{6}$ \\
\hline Pulmonary artery $\mathrm{O}_{2}(\%)$ & 64 & \\
\hline Brachial artery $\mathrm{O}_{2}(\%)$ & $98 \cdot 5$ & \\
\hline Cardiac output (1/min) & $3 \cdot 3$ & \\
\hline Cardiac index $\left(1 / \min\right.$ per $\left.\mathrm{m}^{2}\right)$ & $2 \cdot 0$ & \\
\hline $\begin{array}{l}\text { Systemic vascular } \\
\text { resistance (units) }\end{array}$ & 20 & \\
\hline $\begin{array}{l}\text { Pulmonary vascular } \\
\text { resistance (units) }\end{array}$ & $2 \cdot 1$ & \\
\hline
\end{tabular}

case operation became necessary because of pronounced cyanosis, extreme cardiomegaly, and increasing disability culminating in refractory congestive cardiac failure, features that are all associated with an unfavourable prognosis. It is generally agreed that corrective surgery should be reserved for severe forms of Ebstein's anomaly in functional classes III and IV, with paradoxical emboli, arterial thrombosis, and right ventricular outflow obstruction as additional indications. ${ }^{2}$ While the optimal timing of operation may be when the patient is above 15 years of age $^{3}$ operation is sometimes mandatory at younger ages and it is our
(A)
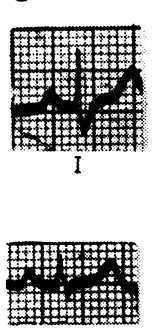

II

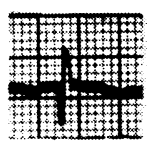

III
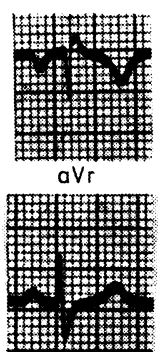

aVI

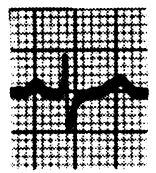

$a V f$

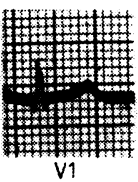

V1

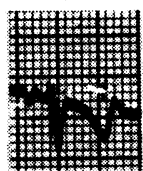

V2

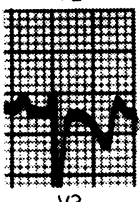

V3

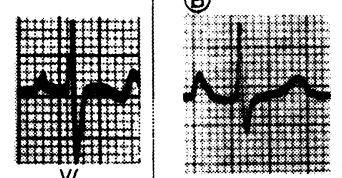

I
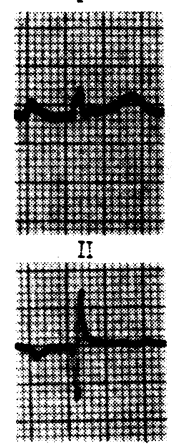

III

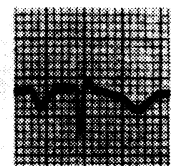

$a V_{r}$

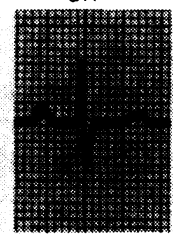

aVI

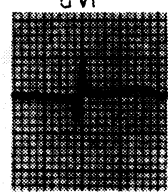

$a \vee f$

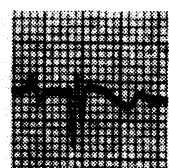

V1

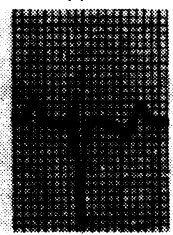

V2

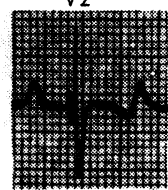

V3

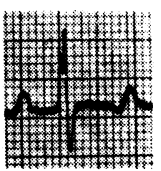

V4

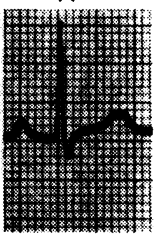

V5

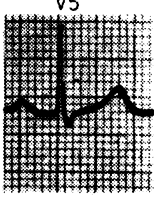

V6

Fig. 2 (A) Electrocardiogram in 1963, one year postoperatively, showing sinus rhythm. PR interval 160 ms and incomplete right bundle-branch block, $Q R S$ duration $100 \mathrm{~ms}$. (B) Electrocardiogram in 1980 showing sinus rhythm, first degree atrioventricular block. $P R$ interval $240 \mathrm{~ms}$, right atrial hypertrophy, and incomplete right bundle-branch block. QRS duration $100 \mathrm{~ms}$. 
policy to undertake definitive correction rather than a palliative procedure regardless of age, assuming a prosthesis of sufficient size can be inserted. Valve replacement at $4 \frac{1}{2}$ years achieved dramatic symptomatic improvement in this severely disabled child and allowed subsequent normal development into adult life without the need for a second major cardiac operation. Despite a mean gradient of $6 \mathrm{mmHg}$ across the prosthesis which presumably has been responsible for increased electrocardiographic evidence of right atrial hypertrophy, cardiac catheterisation showed that the valve has remained haemodynamically beneficial into adult life; in particular it was competent, and was associated with an adequate cardiac output and a normal systemic oxygen saturation.

Major controversy centres upon whether valve replacement or repair should be the preferred surgical approach in Ebstein's anomaly and whether or not plication of the atrialised ventricular segment is necessary. Partly responsible for conflicting opinion is the extreme variability of the structural abnormality and the relative rarity of the condition, so that individual experience is small. Valvular reconstruction or annuloplasty is clearly not appropriate where there is extreme deformity of the tricuspid valve or subvalvar apparatus. Subsequent published experience with definitive surgery has shown that patients are either greatly improved by operation or fail to survive it. In Watson's series from an international co-operative study ${ }^{3}$ the overall surgical mortality for all procedures in 279 cases aged 1 to 15 years was 60.6 per cent. Age was a critical determinant of survival, the surgical mortality for patients over 15 years being halved at 32 per cent. Experience from individual centres has failed to resolve the dilemma as to which is the surgical approach of choice, and the reasons for a high surgical mortality in some series of tricuspid valve replacements are not at all clear. We feel that though the surgical risk in Ebstein's anomaly is high the steady decrease in surgical mortality for cardiac valve replacement in general should be reflected in improved survival for tricuspid valve replacement in this condition too.

Plication of the large atrialised segment of ventricle was not performed in our patient on the basis that the free flow of blood to the lungs would not thereby be compromised, and that the principal determinants of reduced right ventricular output were tricuspid regurgitation and right ventricular outflow obstruction. Angiography has confirmed that the large atrialised segment of the ventricular cavity is inert, acting neither as a ventricular pump nor as a paradoxically moving aneurysm, yet right ventricular output is adequate. Peterffy and Björk ${ }^{4}$ also state that plication is an unnecessary and sometimes dangerous procedure and that the siting of the prosthesis above the atrialised segment is the important factor.

While only limited conclusions may be drawn from a single case we have shown that the procedure described has provided an entirely satisfactory longterm result. Subsequent published experience over 19 years has failed to disclose a clearly superior alternative. The relative insignificance of the arrhythmic and "myocardial" factors in this case of Ebstein's anomaly has favoured the outcome, but these aspects of the disease will not be influenced by any procedure aimed at gross anatomical correction.

We thank the Medical Superintendent, Dr Reeve Saunders, for permission to publish these findings.

\section{References}

1 Barnard CN, Schrire V. Surgical correction of Ebstein's malformation with prosthetic tricuspid valve. Surgery 1963; 54: 302-8.

2 McFaul RC, Davis Z, Giuliani ER, Ritter DG, Danielson GK. Ebstein's malformation. Surgical experience at the Mayo Clinic. F Thorac Cardiovasc Surg 1976; 72: 910-5.

3 Watson H. Natural history of Ebstein's anomaly of tricuspid valve in childhood and adolescence. An international co-operative study of 505 cases $B r$ Heart $\mathcal{F} 1974$; 36: 417-27.

4 Peterffy A, Björk VO. Surgical treatment of Ebstein's anomaly. Early and late results in seven consecutive cases. Scand $\mathcal{F}$ Thorac Cardiovasc Surg 1979; 13: 1-7.

Requests for reprints to Dr R G Charles, Regional Cardiac Centre, Sefton General Hospital, Smithdown Road, Liverpool L15 2HE. 